\title{
Beyond enrolments: a systematic review exploring the factors affecting the retention of Aboriginal and Torres Strait Islander health students in the tertiary education system
}

\author{
Emma V. Taylor (iD, Alex Lalovic(i) and Sandra C. Thompson(1)
}

\begin{abstract}
Background: Indigenous Australians are under-represented in the health workforce, with large disparities between rates of Indigenous and non-Indigenous people in every health profession, including nurses, medical practitioners and all allied health professionals. Yet Indigenous people have long requested to have Indigenous practitioners involved in their health care, with this increasing the likelihood of culturally safe care. To address the shortage of Indigenous health professionals, it is important to not only recruit more Indigenous people into health courses, but also to support them throughout their studies so that they graduate as qualified health professionals.

The aim of this systematic literature review was two-fold: to identify the factors affecting the retention of Indigenous students across all tertiary health disciplines, and to identify strategies that support Indigenous students to remain with, and successfully complete, their studies.
\end{abstract}

Methods: Eight electronic databases were systematically searched between July and September 2018. Articles were screened for inclusion using pre-defined criteria and assessed for quality using the Mixed Methods Assessment Tool and the Joanna Briggs Institute Checklist for Text and Opinion.

Results: Twenty-six articles met the criteria for inclusion. Key factors reported by students as affecting retention were: family and peer support; competing obligations; academic preparation and prior educational experiences; access to the Indigenous Student Support Centre; financial hardship; and racism and discrimination. The most successful strategies implemented by nursing, health and medical science faculties to improve retention were multi-layered and included: culturally appropriate recruitment and selection processes; comprehensive orientation and pre-entry programs; building a supportive and enabling school culture; appointing Indigenous academics; embedding Indigenous content throughout the curriculum; developing mentoring and tutoring programs; flexible delivery of content; partnerships with the Indigenous Student Support Centre; providing social and financial support; and 'leaving the university door open' for students who leave before graduation to return.

Conclusions: Universities have an important role to play in addressing inequities in the Indigenous health workforce. A suite of measures implemented concurrently to provide support, starting with recruitment and pre-entry preparation programs, then continuing throughout the student's time at university, can enable talented Indigenous people to overcome adversities and graduate as health professionals.

Keywords: Indigenous students, Aboriginal and Torres Strait islander, Recruitment, Retention, Attrition, Academic success, Support, Health education, Higher education, Health workforce development

\footnotetext{
* Correspondence: emma.taylor@uwa.edu.au

Western Australian Centre for Rural Health, The University of Western

Australia, 167 Fitzgerald Street, Geraldton, Western Australia 6530, Australia
}

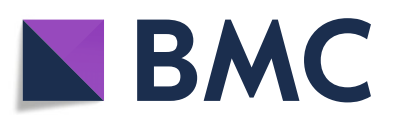

(c) The Author(s). 2019 Open Access This article is distributed under the terms of the Creative Commons Attribution 4.0 International License (http://creativecommons.org/licenses/by/4.0/), which permits unrestricted use, distribution, and reproduction in any medium, provided you give appropriate credit to the original author(s) and the source, provide a link to the Creative Commons license, and indicate if changes were made. The Creative Commons Public Domain Dedication waiver (http://creativecommons.org/publicdomain/zero/1.0/) applies to the data made available in this article, unless otherwise stated. 


\section{Background}

The First Peoples of Australia have richly diverse and complex cultures which have existed for more than 50,000 years. However, colonisation disrupted traditional lifestyles, and discrimination and systemic disadvantage perpetrated upon this group of people means they have continued to experience poor outcomes in education and employment, and disproportionate levels of poor health [1-3]. The health disparity between Aboriginal and Torres Strait Islander peoples and non-Indigenous Australians across a wide range of indicators, including life expectancy, has been well documented for decades $[1,4,5]$. (The term 'Indigenous Australians' is hereafter used respectfully to refer to Australia's Aboriginal and Torres Strait Islander peoples, and with full recognition of the tremendous diversity of the cultures and experiences of Australia's First Peoples.)

There is a growing recognition of the multitude of factors that contribute to the poorer health status of Indigenous Australians [6]. Across the world, there is a strong connection between education and health outcomes, with mounting evidence in Australia and internationally, that successful participation by Indigenous people in higher education provides multiple benefits to the individual and the community [7-10]. Participation in a health sciences degree not only increases the educational attainment and earning potential of the individual with flow on effects to their family and community, it also increases the number of Indigenous people in the health workforce and consequently improves health outcomes for Indigenous people in the community $[3,11-16]$.

Australia urgently needs more Indigenous people within the health workforce. In 2015 they comprised only $1 \%$ of the registered health workforce, despite accounting for $3 \%$ of the Australian population and $4 \%$ of all hospital admissions [2]. Large disparities exist for every health profession, including nurses (in 2015, 1.1\% of all employed nurses and midwives identified as Indigenous) and medical practitioners $(0.5 \%$ of all employed medical practitioners identified as Indigenous) $[17,18]$. Increased enrolment in and successful completion of health science degrees is therefore essential for developing an effective health workforce capable of meeting the needs of Australia's First Peoples [19-21].

Many factors have contributed to the disproportionately small number of Indigenous people attending or completing tertiary education in Australia [10]. These factors range from long-standing historical policies that denied, restricted or segregated access to education $[22,23]$, to financial barriers [24] and current day perceptions that tertiary education, with its European traditions, is alienating, culturally unsafe or simply "not an option" $[10,25,26]$. Federal Government initiatives such as Closing the Gap and national curriculum reform, as well as intensive, sustained efforts by individual universities and faculties have led to a steady increase in the number of student enrolments [10]. Although there has been a $135 \%$ increase over the past decade in the number of Indigenous students enrolling in tertiary health degrees, population parity has not yet been reached, with Indigenous people currently comprising $2.1 \%$ of all commencing domestic health students [27]. Furthermore, improvements in recruitment have not been matched by improvements in retention, with course completions not increasing at the same rate as commencements. In fact, there is a widening gap between Indigenous and non-Indigenous students for health course completions, increasing from $11 \%$ in 2008 to $23 \%$ in 2017 [27]; in some courses, such as nursing, the gap can be much higher [28].

Graduation is only one measure of a good outcome from education and "success" is different for every student. Those who do not graduate may still use the learnings from their time at university in their careers and lives. However, to increase the number of qualified Indigenous health professionals necessitates graduation as a critical measure of success; this requires a focus on retention strategies to support students achieving this.

Despite numerous studies and reviews over the past three decades into the factors affecting success and retention for Indigenous Australians at university [23, 29-33], the majority of research "considers the university as a whole, with analysis of faculty attrition often neglected" ([33], p. 7). Consequently there is minimal evidence around educational strategies that achieve successful outcomes in supporting and retaining Indigenous health science students $[26,34,35]$. The purpose of this systematic literature review is two-fold: to identify factors affecting the retention of Indigenous students across all tertiary health disciplines from a student perspective, and to identify strategies reported by health faculties as effective in supporting those students and assisting retention. Wider promotion of these strategies may lead to them being more broadly adopted, increasing the number of Indigenous students graduating health science courses and becoming health professionals.

\section{Methodology}

The review was conducted in accordance with the principles of the Preferred Reporting Items for Systematic Review and Meta-Analysis (PRISMA) statement [36], to meet standards for accurate and consistent reporting and with the aim of minimising methodological bias.

\section{Search strategy}

The search was conducted between July and September 2018, using database-specific search strings, across the following databases: PubMed, CINAHL, PsycInfo, Embase, Informit: Indigenous Collection, Informit: Health Collection, ERIC and Google Scholar. Key search words of 'health students', 'Indigenous' and 'Australia' were searched using a 
combination of subject headings and free text keywords (see Fig. 1). Back issues of the Australian Journal of Indigenous Education were hand searched, and reference lists of all retrieved articles (including other systematic reviews) were scanned manually.

\section{Screening process: inclusion and exclusion criteria}

We included peer-reviewed empirical studies, peerreviewed descriptive articles and grey literature reports that investigated the enablers or barriers to the retention of Aboriginal and/or Torres Strait Islander students within tertiary health courses, or which described or evaluated strategies to improve the retention of these students. Studies on all health courses were included. Two reviewers (EVT and AL) independently screened titles and abstracts of publications identified using the following predetermined exclusion criteria to determine eligibility for full text review: (i) language other than English; (ii) non-Indigenous students only; (iii) Indigenous population was patients rather than students; (iv) a tertiary course other than health; (v) focused on primary or secondary school students; or (vi) not based on findings from Australia.

The full texts were then independently reviewed with information extracted using a pre-determined data extraction form. Any disagreements regarding article eligibility were discussed and resolved by the two reviewers. A publication was excluded following full text examination if it: (i) included no findings or connection to retention or attrition related to Indigenous students (such as articles that just reported on positive or negative aspects of the course of study, without any connection to retention or attrition); (ii) reported on a tertiary course other than health or a qualification below Bachelor degree level; (iii) did not include a clearly defined Indigenous health student body; or (iv) was a literature review. Multiple papers from the same authors reporting on the same study population were included only if there were differences in the findings.

\section{Quality appraisal}

The quality of the empirical studies $(n=14)$ and grey literature reports $(n=3)$ was assessed using the Mixed Methods Appraisal Tool (MMAT), Version 2018 [37]. The MMAT was selected as it is designed for systematic reviews that include qualitative, quantitative and mixedmethods studies, enabling the use of one tool for appraising the most common types of empirical studies [38] and it has been found to be efficient, reliable and has demonstrated content validity [39, 40]. After responding to two screening questions, each included study was rated in the appropriate category of criteria as either 'yes', 'no' or 'unclear'. Of note, the tool does not address the quality of the reporting, but only the quality of the reported methods of the study. Two reviewers (EVT and AL) independently evaluated the articles.

Descriptive articles $(n=9)$ were assessed for quality by the same two authors using the Joanna Briggs Institute Checklist for Text and Opinion [41]. This tool consists of six criteria and allows for the appraisal of narrative text and expert opinion articles. Included articles were evaluated

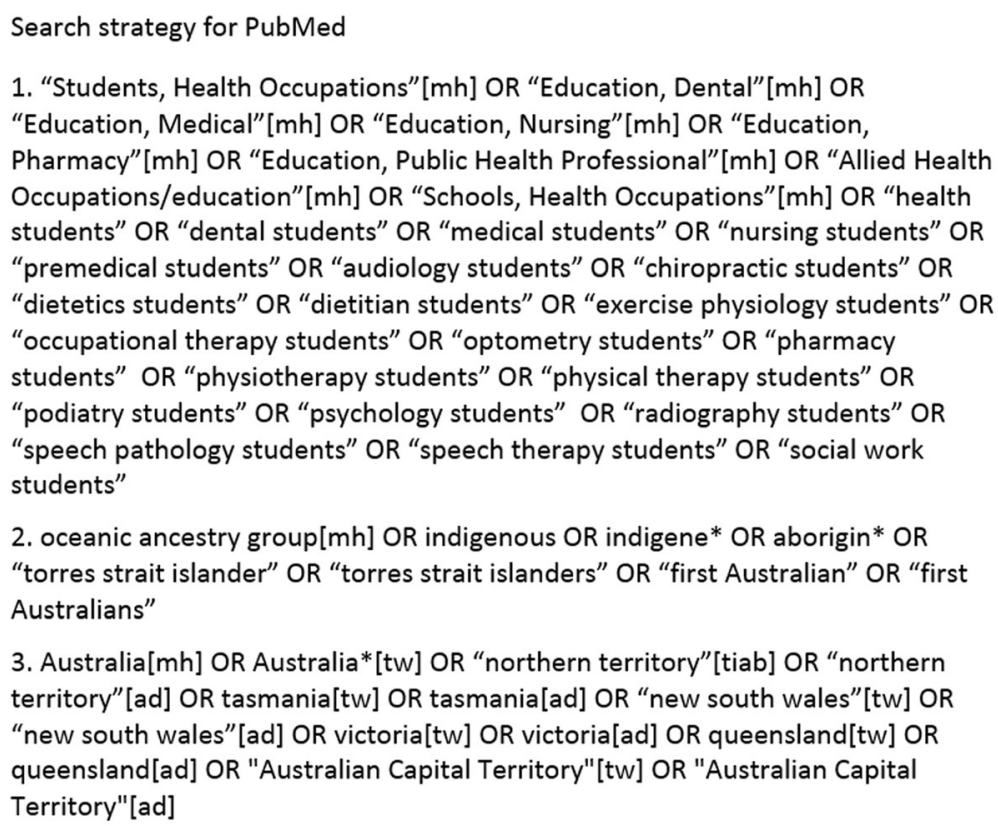

Fig. 1 Electronic database search strategy example* *Search terms varied slightly for each database 
with respect to these criteria which include the established expertise of the author(s), the clarity and logic of the articulated argument, whether there was reference to existing literature and whether any incongruence with the literature was considered and defended [41]. Any score discrepancy was resolved through discussion.

After both quality appraisal tools had been completed and consensus reached, an assessment of 'high', 'medium' or 'low' quality was given to each article. It was decided at the outset that no study would be excluded on the basis of its quality assessment.

\section{Analysis}

There were two components to the analysis of this review, which was conducted by two authors (EVT and AL) and then reviewed and refined by ST. Enablers, barriers, and recommendations relating to retention, as reported by current or former Indigenous students, were identified for each article. Factors affecting retention were then grouped into a matrix, which provided a logical framework to synthesise information. The matrix layout was based on one devised by Slatyer et al. [42] in their article looking at barriers and enablers to retention of Aboriginal Diploma of Nursing students and used with their permission. Finally, a count of identified factors provided a quantitative assessment of how frequently each factor was reported in the included literature.

Identified strategies or interventions to improve retention, as described or evaluated from the school or faculty perspective, were separated into individual components. Components were grouped chronologically to where they occurred during the students' time at university and then mapped to a diagram. The frequency with which each strategy was reported was also assessed.

\section{Results}

We identified 26 articles that met our inclusion criteria. The results for each stage of our search and screening processes are shown in the PRISMA flow diagram (Fig. 2).

\section{Description of studies}

Over half the articles included in this review were empirical $(n=14 ; 54 \%)$ (Table 1$)$. The descriptive articles $(n=9 ; 35 \%)$ (Table 2) described strategies implemented to improve retention from the school or faculty perspective, but did not evaluate those strategies. Grey literature reports on the three main professions represented in the included articles $(n=3 ; 11 \%)$ are outlined in Table 3.

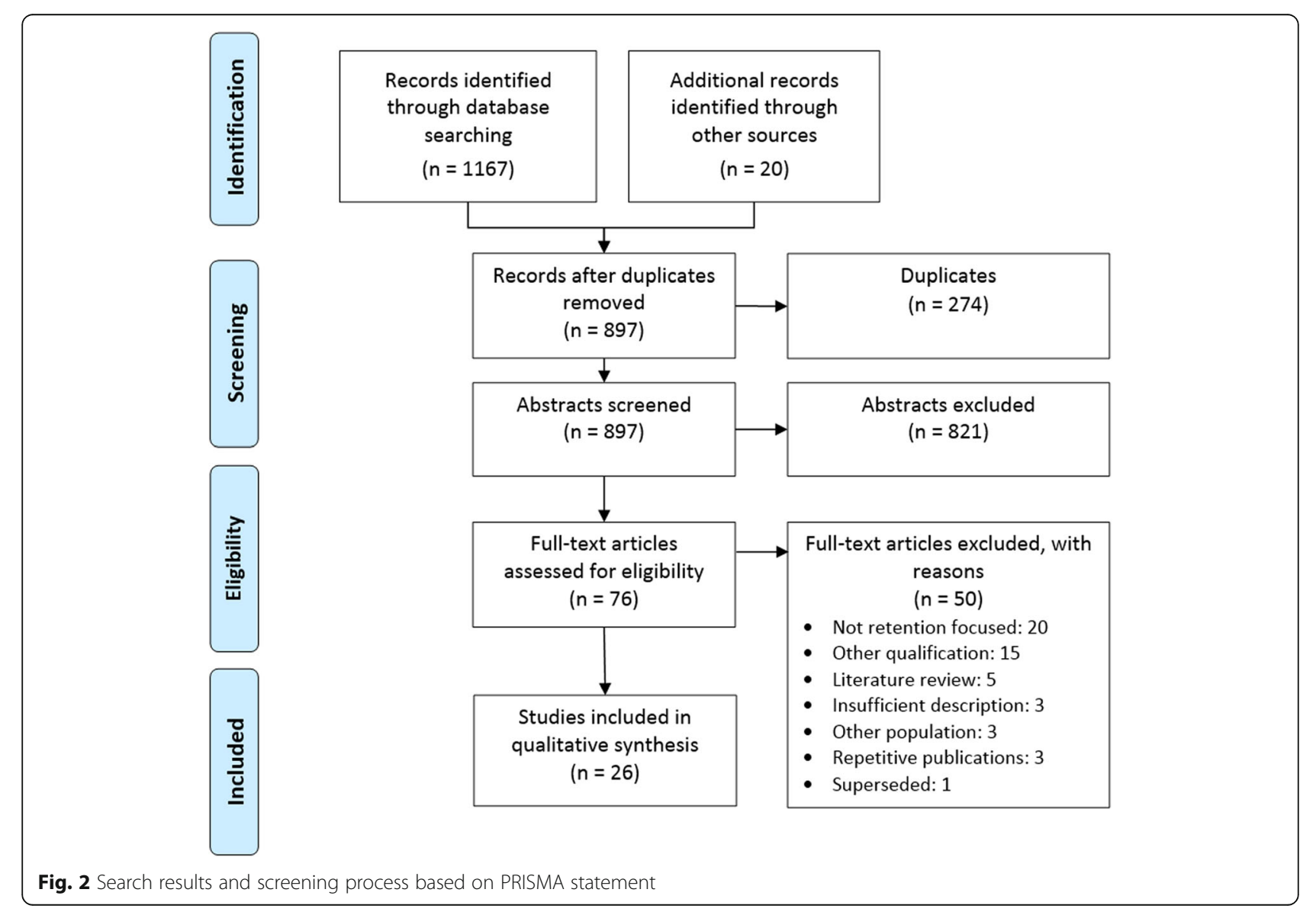


Studies took place in all states and territories except Tasmania and the Australian Capital Territory. The largest number of studies took place in Queensland $(n=8)$ or were national in scope $(n=8)$. Two Queensland authors, West and Usher, were lead author on five of the included articles, all of which focused on issues affecting nursing students.

Half $(n=13)$ of the studies focused on issues affecting nursing and midwifery students $[11,28,34,48-53,55,57,60,62]$, five studies focused on medical students [45, 47, 58, 59, 64], three focused on psychology students $[43,56,63]$, one study focused on public health students [20], and four studies reported on issues affecting Indigenous students across several health disciplines (courses included: dentistry, health science, human movement, medicine, nursing and midwifery, occupational therapy, physiotherapy and podiatry) [44, 46, 54, 61]. No articles reported specifically on the retention of dental students or any of the other allied health courses (such as social work or physiotherapy) apart from psychology.

Eighteen articles were assessed as good quality, six as medium quality, one was assessed as low quality [57] and one grey literature report was not suitable for quality appraisal using the MMAT because it was not an empirical study [63].

\section{Factors affecting retention}

Factors reported by current or former Indigenous students as affecting retention were primarily identified from the empirical research articles. These factors have been represented via a matrix in Fig. 3. Rarely was one of these factors identified in isolation; generally it was the combination across several quadrants that resulted in students remaining or departing.

\section{Student characteristics}

A range of personal support networks were pivotal to students' well-being and to their remaining at university. Family support was the most frequently mentioned enabler for retention $[20,28,43,46,47,50-53,60]$ with family providing support, even when they hadn't had educational opportunities themselves. Family support included emotional, financial and physical support, including when students were far away geographically, and it gave participants the confidence to go to university and encouraged them to remain there. Peer support from fellow Indigenous students, particularly those studying a health course, was also very important [28, 46, 48, 50-52,60]. The value of support from workplaces and professional networks such as the Congress of Aboriginal and Torres Strait Islander Nurses and Midwives (CATSINaM) and the Australian Indigenous Doctors' Association (AIDA) was also identified [44, 47, 50-52]. While not necessarily part of students' support networks, senior Indigenous students and graduates of the course were inspiring and highly motivating role models for students, helping to engender confidence in their studies and encouraging them to stay at university [20, 46, 47, 52]. Conversely, where there was a lack of support or understanding from family or workplace, this contributed to students' feelings of stress, isolation and loneliness [43, 45, $47,50]$.

Internal motivations were a powerful driver for many students, with wanting to make a difference for Indigenous health the most frequently mentioned [28, 44, 45, $50,52,53]$. Students also reported a desire to be a role model and inspire others within their family and community $[50,52,53]$, and to improve their career options and "have a more influential role in [health] policy making" $[45,50,53]$ as motivators for continuing with their studies.

A number of personal attributes were identified in the literature as having a protective effect; confidence, resilience and perseverance were all influential on course completion [46, 48, 51-53]. Some mature aged students reported feeling confidence as a result of their life experiences (previous employment, parenthood, positive educational experiences) and the skills they had acquired (such as study skills, communication, teamwork) [28, 46, $48,51]$. West et al. [28, 52] found that student nurses' ability and willingness to seek out and then accept support was pivotal to successful course completion.

Having competing obligations was the most frequently mentioned barrier to remaining at university, reported by almost half of the included articles [20, 44-48, 50-52, 54, $57,60]$. Competing obligations included difficulties meeting family and community commitments, stress caused by family crises or illness, and difficulties balancing study, work and family. Financial hardship was mentioned by a quarter of articles as a reason for not continuing with study $[20,43,45-47,51,60]$, and in some instances was exacerbated by feelings of shame for seeking financial assistance from others. Usher et al. [51] suggested that students' financial burden had a cultural component as participants reported that they were expected to share money with extended family members, an expectation not usually experienced by non-Indigenous students.

\section{School/faculty characteristics}

Students described a range of cultural and academic support strategies implemented by schools and faculties that helped them continue their studies. Cultural support included supportive non-Indigenous academics and clinicians [28, 43, 50-52] who helped students to feel safe and comfortable at university. Support from Indigenous academics and clinicians was reported by students in three studies as "essential" to their remaining at university $[28,50,52]$. Culturally inclusive teaching and learning practices with consideration of different student learning styles, as well as embedding Indigenous content 
Table 1 Empirical studies

\begin{tabular}{|c|c|c|c|c|c|}
\hline $\begin{array}{l}\text { Author (Year) } \\
\text { Location (University) }\end{array}$ & Methods & $\begin{array}{l}\text { Study Population and } \\
\text { Response Rate }\end{array}$ & Focus & Relevant Findings & $\begin{array}{l}\text { Quality } \\
\text { (MMAT) }\end{array}$ \\
\hline $\begin{array}{l}\text { Cameron et al. } \\
\text { (2014) [43] } \\
\text { Australia (multiple) }\end{array}$ & $\begin{array}{l}\text { Qualitative } \\
\text { Interviews }\end{array}$ & $\begin{array}{l}10 \text { Indigenous psychologists. } \\
\text { Response rate: unspecified. } \\
\text { Purposive sampling and } \\
\text { mass recruitment via e-mail } \\
\text { to all members of } \\
\text { the Australian Indigenous } \\
\text { Psychologists Association. }\end{array}$ & $\begin{array}{l}\text { Psychology } \\
\text { Enablers and barriers } \\
\text { for Indigenous } \\
\text { students studying } \\
\text { psychology. }\end{array}$ & $\begin{array}{l}\text { Sources of support: family } \\
\text { support, financial assistance, } \\
\text { and Indigenous student support } \\
\text { centres. Barriers: fear and anxiety } \\
\text { about attending university, culture } \\
\text { shock when relocating to a } \\
\text { metropolitan area, lack of Indigenous } \\
\text { staff and content, cultural insensitivity } \\
\text { by staff and racism. }\end{array}$ & High \\
\hline
\end{tabular}

Chur-Hansen et al.

(2008) [44]

South Australia

(University of Adelaide)

Ellender et al.

(2008) [45]

Australia (multiple)

Farrington et al.

(2001) [46]

New South Wales

(University of Sydney)
Qualitative 4 Indigenous students

Interviews (1 medicine, 1 dentistry,

2 health sciences).

Response

rate: $100 \%$ of Indigenous

first year students in

the Faculty of

Health Sciences.

Quantitative 12 Indigenous medical

Survey

students who had

deferred or withdrawn

from their course.

Response rate: $9 \%$ of

withdrawn students.

Purposive sampling, mass

recruitment to 130

withdrawn students,

advertisements in

electronic newsletter.

Qualitative

Interviews

26 Cadigal Program students

from the following

courses: physiotherapy,

occupation and leisure

studies, communication and

speech disorders, nursing,

medical radiation

(unclear how many

participated from each course).

Response rate: unspecified.
Health Sciences

Expectations and

Sources of support: wishing to make High

health students at

commencement and after Barriers: lack of knowledge about the

1 year.

\section{Medicine}

Barriers experienced

by 12 Indigenous

medical students

that caused them

to withdraw.

Health Sciences

Factors which influence

participation, progression

and retention of

ndigenous students in

full time health courses. difference for Indigenous he

centre and AIDA.

course, lack of confidence, and family commitments.

Financial problems and relationship

Medium and/or family problems were the two most cited reasons for leaving. Other reasons for withdrawing included: high workload, fatigue, illness and cultural isolation, unclear expectations, and faculty staff. More support from the university may have encouraged respondents to continue.

Sources of support: family, previous positive educational experiences, the Cadigal program and other Indigenous students.

Factors that caused students to contemplate withdrawing: family and personal crises, financial difficulties and racism from non-Indigenous students.

Strategy: the Cadigal program consisted of a two-week orientation program, the option of reduced load during first 2 years combined with the Aboriginal Health Science Support program, peer tutoring and access to facilities and resources.

16 Indigenous medical students.

Response rate: $89 \%$ of Indigenous students enrolled in second or subsequent year
Garvey et al. (2009) [47] Qualitative
Kippen et al. (2006) [20] Victoria

(La Trobe University)
Qualitative Interviews, focus groups
16 participants (14 Indigenous (academics, public health students and key community stakeholders), 2 nonIndigenous public health academics).

Response rate: unspecified. Purposive sampling.
Medicine

Experiences of 16 Indigenous medical students and their perceptions of the factors influencing their progression.

Public Health Enablers and barriers affecting recruitment and retention of Indigenous Public Health students.

Support provided by family, peers, senior Indigenous students and faculty staff was pivotal to students' well-being and progression through training.

Financial difficulties were cited as a reason to withdraw from studies.

Other barriers that affected progression included: homesickness, personal and family issues, lack of confidence and racial discrimination.

Family, positive role models and the Indigenous Student Support Centre were important sources of support. Barriers included: negative past educational experiences, family obligations, lack of Indigenous staff, cultural insensitivity by nonIndigenous staff and lack of formal articulation pathways from VET 
Table 1 Empirical studies (Continued)

\begin{tabular}{|c|c|c|c|}
\hline $\begin{array}{l}\text { Author (Year) } \\
\text { Location (University) }\end{array}$ & Methods & $\begin{array}{l}\text { Study Population and } \\
\text { Response Rate }\end{array}$ & Focus \\
\hline $\begin{array}{l}\text { Mills et al. (2014) [48] } \\
\text { Queensland (James } \\
\text { Cook University) }\end{array}$ & $\begin{array}{l}\text { Qualitative } \\
\text { Interviews }\end{array}$ & $\begin{array}{l}11 \text { Indigenous nursing } \\
\text { students. } \\
\text { Response rate: } 92 \% \text { of } \\
\text { mentoring circle participants. }\end{array}$ & $\begin{array}{l}\text { Nursing } \\
\text { Describes the trial of a } \\
\text { mentoring circle to } \\
\text { support and retain } \\
\text { Indigenous nursing } \\
\text { students in a remote } \\
\text { community. }\end{array}$ \\
\hline
\end{tabular}

Relevant Findings Q Quality

courses.

courses.

Mentoring circle consisting of one or High two mentors and 12 students met regularly over two semesters. Students formed a group identity and provided support to one another. As a group, students identified barriers affecting their ability to succeed at university and resolved those barriers through group discussions. Students identified skills required to succeed at university and developed those skills.

Schulz et al. (2018) [49] Queensland (Australian Catholic University)

Qualitative Focus groups
Stuart et al. (2015) [50] Queensland (Not specified)
10 Indigenous midwifery students.

Response rate: $77 \%$ of Indigenous students enrolled in the Away-from-Base Bachelor of Midwifery degree.
Nursing

Evaluates two enhancements to a Midwifery course: appointment of an Indigenous Academic Liaison Midwife (IALM) and an additional clinical placement in a highvolume tertiary hospital.
Qualitative Interviews, focus groups
5 Indigenous nursing students Nursing (former Indigenous Health Workers). Response rate: $100 \%$ of eligible students.
Enablers and barriers experienced by Indigenous Health Workers studying Bachelor of Nursing.
Usher et al. (2005) [51] Australia (multiple)
Qualitative Interviews
22 Indigenous nursing students. Response rate: unspecified. Purposive sampling.
Nursing

Enablers and barriers experienced by Indigenous student nurses.
Regular contact with the IALM helped students stay connected with and focussed on their study. Students respected the IALM as a culturally appropriate professional role model, who provided encouragement, cultural support and advocacy.

The one week placement in a highvolume tertiary hospital was designed to minimise time students spent away from community. Students were supported by hospital staff and the IALM to ensure close supervision and culturally sensitive support.

Recognition of prior learning and course exemptions alleviated workload stress and enabled students to complete their degree faster.

Support from the Indigenous nurse academic and receiving financial support were cited as essential for students to remain at university. Other sources of support included: the Indigenous student support centre, a personal desire to make a difference and the support of family, workplace and other Indigenous students.

All participants reported encountering racism during their course, which impacted on their desire to remain at university.

Adequate financial support was cited High as critical for students to continue with their studies.

Other important sources of support included: Indigenous Student Support Centres, support from nonIndigenous academics, support from family and other students and flexibility within the course. Challenges faced by students included racism, isolation and homesickness, family obligations and lack of adequate educational preparation.

National average completion rates
High 
Table 1 Empirical studies (Continued)

\begin{tabular}{|c|c|c|c|c|c|}
\hline $\begin{array}{l}\text { Author (Year) } \\
\text { Location (University) }\end{array}$ & Methods & $\begin{array}{l}\text { Study Population and } \\
\text { Response Rate }\end{array}$ & Focus & Relevant Findings & $\begin{array}{l}\text { Quality } \\
\text { (MMAT) }\end{array}$ \\
\hline Australia (multiple) & $\begin{array}{l}\text { methods } \\
\text { Data analysis } \\
\text { and } \\
\text { interviews }\end{array}$ & $\begin{array}{l}\text { nursing. } \\
\text { Sample size: } 65 \% \text { of nursing } \\
\text { schools. } \\
\text { Interviews: } 8 \text { Indigenous } \\
\text { nursing students, } 13 \text { nursing } \\
\text { academics (5 Indigenous, } 8 \\
\text { non-Indigenous). } \\
\text { Response rate: unspecified. } \\
\text { Purposive sampling. }\end{array}$ & $\begin{array}{l}\text { Enrolment and } \\
\text { completion rates for } \\
\text { Indigenous student } \\
\text { nurses across Australia. } \\
\text { Student and staff } \\
\text { perceptions of enablers to } \\
\text { successful course } \\
\text { completion. }\end{array}$ & $\begin{array}{l}\text { are } 36.3 \% \text { for Indigenous nursing } \\
\text { students and } 64.6 \% \text { for non- } \\
\text { Indigenous nursing students (a } \\
\text { difference of } 28.3 \% \text { ). } \\
\text { Individual student characteristics } \\
\text { such as motivations for study, } \\
\text { personal attributes (such as seeking } \\
\text { support) and previous life and work } \\
\text { experiences strongly affected their } \\
\text { likelihood of successful completion. } \\
\text { Family support, support from both } \\
\text { Indigenous and non-Indigenous } \\
\text { academics was also deemed critical } \\
\text { for success. }\end{array}$ & \\
\hline
\end{tabular}

West et al. (2016) [52] Queensland (Not specified)
Qualitative Interviews students. Response rate: unspecified. Purposive sampling.
West et al. (2016) [53] Queensland (Not specified)
Qualitative Interviews

3 Indigenous midwifery students.

Response rate: $100 \%$ of students who had provided continuity of care to Indigenous women.

33 current or former Indigenous students (17 nursing, 4 midwifery, 4 human movement, 1 occupational therapy, 3 physiotherapy, 1 podiatry, 1 naturopathy, 2 other).

Response rate: $32 \%$ of Indigenous students who had been enrolled in a health sciences course between 2000 and 2005.
Nursing Indigenous nursing students' perspectives enablers and barriers to their successful course completion.
Racism was identified as one of the biggest barriers to successful course completion.

Previously identified barriers such as financial hardship and academic preparedness were no longer barriers due to students being more prepared to seek support. Students willingness to embrace support was identified as critical to successful course completion. Other personal. attributes such as perseverance and a desire to make a difference for Indigenous health helped students to remain with their studies.

Nursing The relationships the students had Experiences of Indigenous with the Indigenous women, and the midwifery students affirmation they received from those providing continuity of women and the wider community, care to Indigenous gave students confidence and women. provided them with the motivation and resilience to continue with their studies.

Health Sciences Investigates reasons for attrition of Indigenous health students and looks at support service usage.

Students' reasons for withdrawing were varied and multifactorial. The most cited reason was difficulty balancing competing obligations. Other reasons for withdrawing included: literacy struggles, and lack of communication from the university leading to feelings of isolation and disengagement. Financial support and flexible delivery were identified as allowing students to remain with their studies when they otherwise would have withdrawn.

\begin{tabular}{|c|c|c|}
\hline $\begin{array}{l}\text { South Australia } \\
\text { (University of South } \\
\text { Australia) }\end{array}$ & Survey & $\begin{array}{l}\text { Indigenous students ( } 17 \\
\text { nursing, } 4 \text { midwifery, } 4 \text { human } \\
\text { movement, } 1 \text { occupational } \\
\text { therapy, } 3 \text { physiotherapy, } 1 \\
\text { podiatry, } 1 \text { naturopathy, } 2 \\
\text { other). } \\
\text { Response rate: } 32 \% \text { of } \\
\text { Indigenous students who had } \\
\text { been enrolled in a health } \\
\text { sciences course between } 2000 \\
\text { and } 2005 \text {. }\end{array}$ \\
\hline
\end{tabular}

into the curriculum, was reported as assisting retention by students in four studies [28, 51, 52, 63].

Racism and discrimination were barriers reported in over a quarter of included studies [43, 46, 47, 50-52, 64], with West et al. [52] describing racism and discrimination as "one of the most pervasive and debilitating barriers to successful course completion" (p. 353). Examples ranged from questioning the student's Indigeneity, to discrimination and a lack of acceptance by students and staff because the student was viewed as receiving 'special treatment'.

Schools or faculties could support students academically by being flexible in their delivery of course content and allowing students to move between study modes (internal/ external, full-time/part-time) [28, 51, 54]. This was reported as enabling individuals to modify their mode of study according to personal needs, allowing them to "hang-in there" ([54], p. 40). Access to tutors [52, 54, 63] 
Table 2 Descriptive studies

\begin{tabular}{|c|c|c|c|c|c|}
\hline $\begin{array}{l}\text { Author (Year) Location } \\
\text { (University) }\end{array}$ & Methods & $\begin{array}{l}\text { Study } \\
\text { Population }\end{array}$ & Focus & Relevant Findings & $\begin{array}{l}\text { Quality } \\
\text { (JBI } \\
\text { T\&O) }\end{array}$ \\
\hline $\begin{array}{l}\text { Best et al. (2014) [34] } \\
\text { Queensland (University } \\
\text { of Southern } \\
\text { Queensland) }\end{array}$ & $\begin{array}{l}\text { Qualitative } \\
\text { Descriptive }\end{array}$ & None & $\begin{array}{l}\text { Nursing } \\
\text { Describes the Indigenous nursing } \\
\text { support model: Helping hands. }\end{array}$ & $\begin{array}{l}\text { The model is designed to individually } \\
\text { mentor and support Indigenous nursing } \\
\text { students. It consists of five steps: } \\
\text { recruitment, orientation, retention, } \\
\text { graduation and a supporting resource } \\
\text { kit. } \\
\text { Since implementing the model } 80 \\
\text { Indigenous nurses and midwives have } \\
\text { graduated from the program. }\end{array}$ & High \\
\hline
\end{tabular}

Fowler et al. (2018) [55] Qualitative None Western Australia (Edith Descriptive Cowan University)

Harris et al. (2012) [56]

New South Wales

Qualitative Unspecified

(Charles Sturt

University)

Hinton et al. (2010) [57]

Northern Territory

Qualitative

Descriptive

(Batchelor Institute of

Indigenous Tertiary

Education)

Holliday et al. (2015)

[58]

New South Wales

(University of

Newcastle, University of

New England)

\section{Lawson et al. (2007)}

[59]

Australia (University of

Newcastle, University of Western Australia,

James Cook University) Descriptive pre-medical students. from three universities.
Nursing

Describes a conceptual framework and recruitment, retention and academic success of Indigenous nursing students.

Psychology

Describes a model designed to address barriers for Indigenous psychology students.

Nursing

Describes strategies implemented to improve Indigenous nursing students preparedness for entering the workforce.

Qualitative 18 Indigenous

Medicine

Describes and evaluates the Miroma Bunbilla pre-entry to medicine program for Indigenous medical students.

Medicine

$\begin{array}{ll}\text { Qualitative } & \text { Key } \\ \text { Descriptive } & \text { representatives }\end{array}$

Describes the efforts of three medical schools to train and graduate Indigenous medical students. the action taken to support the

The Aboriginal and Torres Strait Islander High Inclusivity Working Group (ATSIIWG) conceptual model consists of five elements: culturally responsive curriculum, cultural events, staff education, student involvement and community involvement.

Key elements of the model are: a whole-of-institution approach embedding Indigenous content into the curriculum, partnership with the local area health service, mentoring and involvement of local elders and communities.

Key strategies implemented were: holistic financial support (including accommodation, meals and free travel), a course timetable focused on reducing impact to family commitments while maximising clinical placement and nursing lab time, and a hospital-based mentoring program to support students while on clinical placement

The program is designed to strengthen the selection process for Indigenous medical students, ensure students have the required skills and improve retention. The program consists of a five day pre-entry intensive course.

Students who completed the program in its first year had a 100\% retention rate in their first year of study and gave positive feedback about the program.

Key strategies included: schooldetermined quotas for Indigenous students, alternative entry schemes, premedical preparation programs, flexible pathways into medicine and academic, social and personal support during the course.

A rigorous selection process that assesses motivation, support structures and ability to balance study with other commitments helps to improve retention rates by selecting students who are more likely to successfully complete the course.

Key strategies included: a streamlined and culturally-safe selection and

Describes strategies to increase the $\begin{array}{ll}\text { recruitment, retention and graduation of admission process, a flexible study } \\ \text { Indigenous nursing students. } & \text { program including offering 'leave of }\end{array}$
High relationship between the school and the Indigenous Student Support Centre,

Queensland

(Queensland University

of Technology)
Qualitative
Descriptive 
Table 2 Descriptive studies (Continued)

\begin{tabular}{|c|c|c|c|c|c|}
\hline $\begin{array}{l}\text { Author (Year) Location } \\
\text { (University) }\end{array}$ & Methods & $\begin{array}{l}\text { Study } \\
\text { Population }\end{array}$ & Focus & Relevant Findings & $\begin{array}{l}\text { Quality } \\
\text { (JBI } \\
\text { T\&O) }\end{array}$ \\
\hline & & & & $\begin{array}{l}\text { tutoring, personal contact with students, } \\
\text { promoting peer networks and } \\
\text { addressing racism. }\end{array}$ & \\
\hline $\begin{array}{l}\text { Paul (2013) [61] } \\
\text { Western Australia } \\
\text { (University of Western } \\
\text { Australia) }\end{array}$ & $\begin{array}{l}\text { Qualitative } \\
\text { Descriptive }\end{array}$ & None & $\begin{array}{l}\text { Health Sciences } \\
\text { Describes strategies to increase the } \\
\text { recruitment and retention of Indigenous } \\
\text { students studying medicine, dentistry } \\
\text { and health sciences. }\end{array}$ & $\begin{array}{l}\text { Key strategies included: alternative entry } \\
\text { pathways for Indigenous students, } \\
\text { individually tailored educational } \\
\text { pathways (including a } 1 \text { year orientation } \\
\text { course and a } 5 \text { week pre-medicine/pre- } \\
\text { dentistry program), comprehensive and } \\
\text { ongoing support for students } \\
\text { throughout their degree (including } \\
\text { access to resources, tutoring, assistance } \\
\text { with applying for financial support and } \\
\text { personal support), and integration of } \\
\text { Indigenous content throughout } \\
\text { curriculum. }\end{array}$ & High \\
\hline $\begin{array}{l}\text { Usher et al. (2005) [62] } \\
\text { Queensland (James } \\
\text { Cook University) }\end{array}$ & $\begin{array}{l}\text { Qualitative } \\
\text { Descriptive }\end{array}$ & None & $\begin{array}{l}\text { Nursing } \\
\text { Describes a Bachelor of Nursing course } \\
\text { being delivered in the Torres Strait, } \\
\text { incorporating specific strategies to } \\
\text { improve recruitment and retention. }\end{array}$ & $\begin{array}{l}\text { A satellite campus was established in a } \\
\text { remote location with the aim of } \\
\text { increasing recruitment of local } \\
\text { Indigenous students and providing a } \\
\text { more supportive environment that } \\
\text { would lead to improved student } \\
\text { retention. } \\
\text { Key strategies included: employing local } \\
\text { people, establishing a community } \\
\text { consultative committee, a structured } \\
\text { timetable with additional contact time } \\
\text { to provide extra support, access to } \\
\text { study resources, tutoring and } \\
\text { establishing a mentoring program. }\end{array}$ & High \\
\hline
\end{tabular}

and mentoring [63, 64] helped create a safe, supportive space for students.

The Indigenous Student Support Centre was reported by participants in a third of articles $[20,28,43,44,46$, $47,50-52]$ as providing academic, social, emotional and cultural support, including tutoring, and advice on finances, scholarships and accommodation. Receiving financial assistance such as a scholarship, cadetship, or ABSTUDY (special government benefits for Indigenous students in an approved course of study), helped students to remain with their studies, especially during clinical placements when they generally had to take leave from their paid employment [43, 50-52, 54, 63].

During the recruitment and preparation stages, students reported that recognition of their existing skills and prior learning helped them feel "empowered" and valued; when course exemptions were granted, this contributed to improved retention by helping students complete their degree faster and reducing financial pressures [50, 63]. Comprehensive orientation programs helped students to understand school or faculty expectations, meet other students and feel accepted and welcomed by staff $[46,51]$. Conversely, a challenging admission process, such as a lack of formal pathways from vocational education and training (VET) courses that articulated with university studies, or difficulties applying for recognition of prior learning (particularly for Indigenous Health Workers), contributed to students feeling stressed, disempowered and undervalued $[20,50,60,64]$.

\section{Strategies to improve retention}

Descriptions of strategies or programs implemented by health schools or faculties to improve retention were primarily identified from the descriptive articles, and are represented chronologically in Fig. 4.

\section{Recruitment}

Multiple articles, predominantly those looking at strategies implemented in medical schools, claimed that retention starts with appropriate selection [58-60, 64]. Medical schools aimed to select students who would successfully complete the course by looking at applicants' motivations, support structures and ability to balance study with other commitments. Lawson et al. [59], in their discussion of the strategies adopted by the three leading universities regarding Indigenous student enrolment in medicine, reported a strong link between selection and retention, although they acknowledged the need to achieve a balance between achieving a high completion rate and giving "higher-risk" students a chance. Two articles emphasised the importance 
Table 3 Grey literature

\begin{tabular}{|c|c|c|c|c|c|}
\hline $\begin{array}{l}\text { Author (Year) } \\
\text { Location }\end{array}$ & Methods & $\begin{array}{l}\text { Study Population and } \\
\text { Response Rate }\end{array}$ & Focus & Relevant Findings & $\begin{array}{l}\text { Quality } \\
\text { (MMAT) }\end{array}$ \\
\hline $\begin{array}{l}\text { Dudgeon et al. } \\
\text { (2016) [63] } \\
\text { Australia }\end{array}$ & $\begin{array}{l}\text { Qualitative } \\
\text { Consensus }\end{array}$ & $\begin{array}{l}\text { None. } \\
\text { Working party consensus with } \\
\text { input from Indigenous } \\
\text { stakeholders. }\end{array}$ & $\begin{array}{l}\text { Psychology } \\
\text { Guidelines for increasing the } \\
\text { recruitment, retention and } \\
\text { graduation of Indigenous } \\
\text { psychology students. }\end{array}$ & $\begin{array}{l}\text { Thirteen critical factors for increasing } \\
\text { recruitment, retention and graduation: } \\
\text { community partnerships, organisational } \\
\text { leadership and enabling culture, } \\
\text { mentors and role models, tutoring and } \\
\text { academic support, scholarships and } \\
\text { financial assistance, curriculum and } \\
\text { pedagogy, community and family links, } \\
\text { peer networks, IEC relationships, } \\
\text { outreach and school visits, enabling } \\
\text { and bridging programs, alternative } \\
\text { entry, and quotas and designated } \\
\text { places. }\end{array}$ & N/A \\
\hline
\end{tabular}

$\begin{array}{llll}\text { Indigenous } & \text { Quantitative } & \text { 22 schools of nursing. } & \text { Nursing } \\ \text { Nursing } & \text { Survey } & \begin{array}{l}\text { Response rate: 73\% of nursing } \\ \text { schools. }\end{array} & \begin{array}{l}\text { Framework to improve } \\ \text { Education }\end{array} \\ \text { Working Group } & & & \text { nursing education. }\end{array}$

(2002) [11]

Australia
There is room for improvement regarding recruitment and retention strategies for Indigenous nursing students.

Few schools of nursing have integrated Indigenous health into their core nursing curriculum.

Makes 32 recommendations to improve Indigenous nursing education covering: recruitment, retention, curriculum development and implementation, advanced nursing practice and postgraduate education, articulation, partnerships and networks, and monitoring and accountability.

Evidence that Indigenous medical students may have significantly higher withdrawal rates than non-Indigenous students.

Quality and sustainability of recruitment and retention strategies for Indigenous medical students requires considerable attention within the majority of medical schools.

Racism and discrimination remain a significant issue in the majority of Australian medical schools.

Makes 10 recommendations to improve Indigenous medical education.

N/A Not applicable. This publication was not suitable for quality appraisal with the MMAT scoring system

of selecting students through a culturally appropriate interview process $[60,64]$. The importance of offering multiple pathways into medicine was also stressed [58, 59, 61, 64].

Three studies identified the importance of a cohort effect with Indigenous students enabling peer learning and support $[46,58,60]$, while others identified the importance of course quotas with specific places available for Indigenous students $[11,59]$. Being with other Indigenous students directly benefitted students' academic success and likelihood of retention, reflecting the moral and academic support students can provide to one another. For example, Meiklejohn et al. [60] concluded (p. 7):

"A critical mass of eight students has been identified as the minimum number of enrolees at any one time likely to result in successful completion of studies.
Numbers of less than eight may leave students feeling isolated, and without study partners, encouragement and peer support."

\section{Preparation}

Articles described pre-entry preparation programs and comprehensive orientation programs as an effective way to inform students about the support available to them at university, as well as communicating university expectations and managing student expectations. Descriptions of pre-entry preparation programs were relatively common $[54,56,58,59,61,64]$, although predominately employed by medical schools. Courses described as "pre-entry" varied substantially in terms of the aims, content covered and duration, with examples ranging from 5 days to 1 year. 


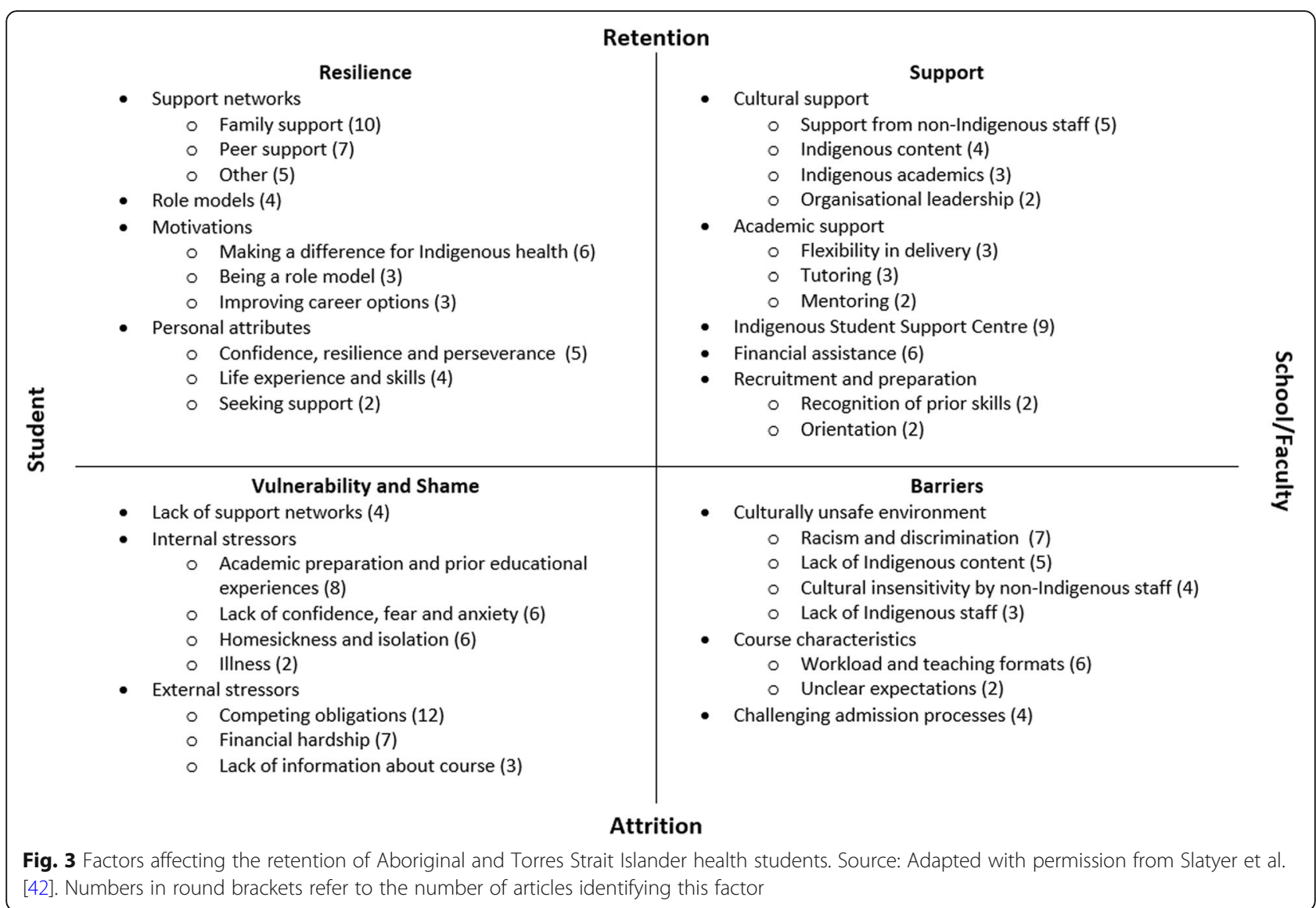

Holliday et al. [58] described a comprehensive 5 day preentry to medicine intensive course which demonstrated positive outcomes, including $100 \%$ retention rate during first year for participants of the program, and "overwhelmingly" positive feedback from students. Comprehensive orientation programs were less commonly described [34, $46,58]$ and ranged from 1 day to 2 weeks in duration. As one component of the Indigenous Nursing Support (INS) model: Helping Hands, Best et al. [34] described an orientation tool developed for Indigenous student nurses, which included the 'Dandiiri' orientation breakfast, a special enrolments area and formally allocated staff support.

\section{Time at university}

Providing cultural support for Indigenous students was recognised as needing to come "from the top", with over a quarter of the articles reporting strong organisational leadership and a deliberate attempt to foster an enabling culture within their schools or faculties [28, 34, 55-57, 59, 64]. Leadership at the institutional and faculty or school level had flow-on effects within the organisational hierarchy, creating an enabling culture which incorporated Indigenous knowledge and sought to support and respect the Indigenous identity of students. Fostering cultural safety required commitment from every academic rather than relying on one or two motivated staff or only Indigenous staff.

Schools and faculties also demonstrated a commitment to cultural safety by implementing cultural awareness training for non-Indigenous academics and students [11, $55,56,64]$. However, a review co-authored by the Medical Deans Australia and New Zealand (Medical Deans) and AIDA [64] found that these programs were generally targeted towards students rather than staff, that attendance was voluntary and they were often viewed as being "tokenistic and counterproductive" (p. 35). Specific strategies to address racism were only reported in two articles $[59,60]$. Meiklejohn et al. [60] briefly described a number of implemented strategies to address racism including offering counselling and ongoing support to the victims, an address by the Head of School to the student body and disciplinary action taken against the perpetrators, however, there was no indication of how successful these strategies were. Stuart et al. [50] recommended implementing a formal complaint process (including an anonymous hotline number) and employing Indigenous counsellors to give advice to staff and students as a response to the racism commonly experienced by the participants in their study.

Indigenous academics supported students culturally and academically [28, 34, 44, 49, 50, 62] with regular contact 

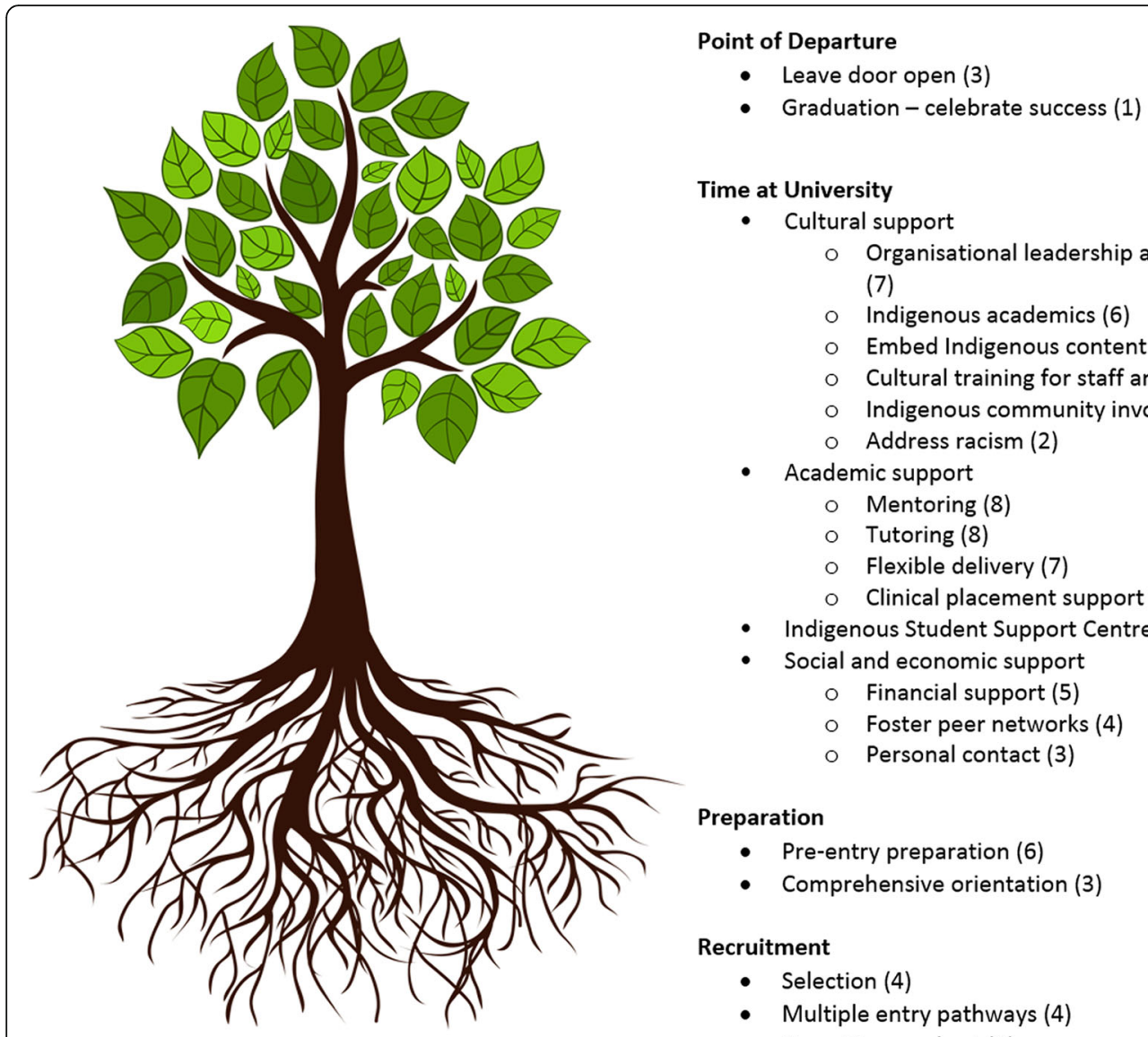

- Leave door open (3)

- Graduation - celebrate success (1)

Time at University

- Cultural support

- Organisational leadership and fostering an enabling culture (7)

- Indigenous academics (6)

- Embed Indigenous content throughout curriculum (5)

- Cultural training for staff and non-Indigenous students (4)

- Indigenous community involvement and collaboration (4)

- Address racism (2)

- Academic support

○ Mentoring (8)

○ Tutoring (8)

- Flexible delivery (7)

- Clinical placement support (4)

- Indigenous Student Support Centre (7)

- Social and economic support

- Financial support (5)

- Foster peer networks (4)

- Personal contact (3)

\section{Preparation \\ - Pre-entry preparation (6) \\ - Comprehensive orientation (3)}

\section{Recruitment \\ - Selection (4) \\ - Multiple entry pathways (4) \\ - Recruiting a cohort (3) \\ - Quotas (2)}

Fig. 4 Strategies for growing strong students. Numbers in round brackets refer to the number of articles identifying this strategy

helping students stay connected and focused on their studies. Schulz et al. [49] describes how the new Indigenous Academic Liaison Midwife (IALM) was respected by students "as a culturally appropriate professional role model" who advocated for students with the other academics, with one student stating "if it wasn't for [the IALM] I wouldn't have made it this far" (p. 62). Also supporting students culturally and academically was the inclusion of Indigenous content in the core health curriculum [34, 55, 56, 61, 64], which made the curriculum more relevant for Indigenous students (increasing the likelihood of retention) and reinforced the belief that Indigenous health issues were worthy of discussion $[34,56]$. Two articles described how Indigenous content was developed in consultation with local Indigenous people to ensure that materials were respectful and safe $[55,64]$. None of the articles described the exact nature of the Indigenous content, only that it "foregrounds Indigenous world views, cultures and experiences" ([56] p. 131), although an audit of the curriculum of all Australian medical schools by Medical Deans et al. [64] found that Indigenous health content covered a wide range of topics including "rural Indigenous health, cultural awareness and cultural implications for health, Indigenous history, communication, clinical presentations of disease, population health and social determinants of health" (p. 12). The amount of Indigenous content incorporated into the curriculum varied amongst the five articles and ranged from one core undergraduate unit $[34,55]$ to a combination of core units and electives throughout the course [56, 61], to Indigenous health not being taught discretely but as "integrated components of broader subject areas" ([64] p. 12). Schools and faculties reported involving the local community through service programs, clinical placements at the local Aboriginal Medical Service, and talks from Elders and local community members $[34,55,56,62]$.

The two most commonly described strategies to provide academic support were targeted mentoring programs [11, $34,48,57-59,62,64]$ and tutoring [11, 34, 46, 58-62]. Mills et al. [48] described the implementation of mentoring circles (a form of group mentoring) as a successful way to support Indigenous nursing students during their studies by empowering them to develop the skills they identified as needing to complete their studies. The review by Medical Deans et al. [64] described a mentoring program where 
social and academic support and professional guidance was provided by experienced (non-Indigenous) clinicians, with some students regarding the mentors as "akin to Elders" (p. 33). Four articles briefly described strategies to support nursing students during clinical placement [34, 49, 53, 57]. Best et al. [34] mentions the "Coolamon clinical school" as a service that provides "support with clinical nursing placements for all Indigenous nursing students" although the exact nature of that support was not specified (p. 64).

Flexibility in the delivery of course content was another way to support students academically [11, 46, 49, $56,57,60,62]$. Some schools or faculties aimed to reduce the travel burden to students by delivering the course in block mode, and Hinton et al. [57] described a Bachelor of Nursing timetable that specifically focused on reducing any impact to family commitments while maximising clinical placement and lab time. Both Meiklejohn et al. [60] and Farrington et al. [46] described how students could choose to reduce their study load, while concurrently completing tutoring or an Aboriginal health science support program, with participants in Farrington's study reflecting that they would not have coped with a full load.

The two most commonly described strategies to provide social and economic support were financial support [11, 57, 59-61] and fostering peer networks [34, 48, 55, 60]. Descriptions of financial support included: assistance applying for scholarships and cadetships; access to class sets of text books, laptops, diagnostic kits; and funding to attend conferences or a travel allowance during clinical placements. Schools supported and encouraged Indigenous students to network by organising social events such as breakfasts and morning teas as an informal way for students to meet. No articles reported on strategies to encourage networking between Indigenous and nonIndigenous students, although Harris et al. [56] described a planned buddy system that would encourage Indigenous and non-Indigenous students to work together to "provide first-hand experience of reconciliation in action, and important exposure to perspective taking" (p. 133). A small number of articles described 'personal contact' as a strategy for retaining students [34, 60, 64], with feedback from students in one study indicating that this was "critical to success" ([64], p. 33).

\section{Point of departure}

Only Best et al. [34] mentioned the importance of celebrating graduation, with the inclusion of a graduation tool within the INS model: Helping Hands to help nursing students celebrate their success. However, Harris et al. [56] described how progress was recognised throughout a Graduate Diploma in Psychology program, by providing a certificate after the first year was completed and a diploma at the end of second year. This had the added advantage of providing "exit points" throughout the qualification. Harris et al. [56] explains (p. 133):

"The reality is that not all students will make it through a 3- or 4-year degree. For many students who are the first generation of their family to attend university, a certificate or diploma recognising what they have done is an accomplishment. It provides a way to exit without losing face, and hopefully encourages them to come back, or, to pursue some other tertiary qualification. It also signals to an employer that the student has attempted tertiary training in psychology."

The importance of "leaving the university door open" for students who left before graduation, was also mentioned in two other articles $[59,60]$. Strategies to prevent students withdrawing unnecessarily included offering a leave of absence when a student's progress stalled due to outside factors, and the option of transferring to a less onerous course of study for a year if the student is struggling academically.

\section{Discussion}

This paper has explored issues associated with retaining Indigenous Australian students in tertiary health courses and identified 26 articles reporting factors affecting retention or that described strategies implemented by schools or faculties to improve retention. Despite the pressing need for Indigenous health professionals, there were relatively few published strategies to improve the retention of health students, minimal documented evaluation of these strategies and no intervention trials, with limited evidence about which retention strategies are most effective. Far more has been written about the factors affecting retention, possibly reflecting the ease with which challenges can be described and the difficulties with achieving robust evidence into what makes a difference in improving outcomes.

Key factors reported by students as affecting retention were: family and peer support; competing obligations; academic preparation and prior educational experiences; access to the Indigenous Student Support Centre; financial hardship; and racism and discrimination. This accords with the findings of previous national and international reviews on Indigenous nurses $[19,26,65]$, as well as findings about the retention of Indigenous health students in vocational education $[42,66,67]$ and Indigenous Australians in other fields of study [68-70].

The majority of retention strategies reported in the literature were focussed solely on the students' time at university, with recruitment and retention often tackled as separate issues. However, we found that recruitment and retention are linked, with persuasive reports that the process of 
selection and preparation for university is critical to a student's retention [58, 59, 64]. Using the metaphor of a tree, if a tree doesn't have strong roots, it may still grow, but the trunk won't be as strong to withstand winds, and the tree won't produce as many leaves, flowers or fruits. In the same way, if the groundwork isn't done with the students - if they aren't informed about the support available to them at university or the expectations of the course prior to starting, if they don't acquire the skills they might need, then they are likely to struggle at university, especially if other challenges occur in their life. We chose to represent the strategies implemented within universities for retaining students using the tree analogy, with the strategies grouped chronologically based on where they supported a student during their study timeline (see Fig. 4).

Despite racism and discrimination being reported as major barriers to retention by students and academics across multiple studies [43, 46, 47, 50-52, 64], few schools or faculties mentioned racism as an issue within their institution and only two articles gave specific examples of strategies to address racism [59,60]. While broader strategies such as organisational leadership and fostering an enabling culture, and cultural training for staff and students, are clearly aimed at creating a safe place for Indigenous students, there seemed to be a lack of willingness to acknowledge either institutional or interpersonal racism as a problem. This may be because schools and faculties lacked insight, because they feared repercussions for admitting that racism existed in their faculty, or because they felt racism was adequately addressed by university-wide policies. Anecdotally there seems to be a lot of uncertainty about appropriate strategies to address racism within schools and faculties. A report by Rodgers-Falk et al. [70] exploring initiatives in the higher education sector to increase the number of Indigenous Australian law graduates, states that "we cannot develop [Aboriginal and Torres Strait Islander] inclusiveness effectively without being able to identify racism, understand its gravity, and being prepared to deal with it. Schools need to have a racism strategy that includes - responding, reprimanding, and policy implementation" (p. 3). The Universities Australia 'National best practice framework for Indigenous cultural competency in Australian universities' may be a useful guide, as it is designed to provide universities with the tools required to create culturally supportive environments for Aboriginal and Torres Strait Islander students and staff [71].

One notable gap in the literature was any investigation of Indigenous students' experiences while on clinical placement and whether their experiences had any effect on their decision to remain with or depart from their studies. In addition, there was a lack of reported strategies to support Indigenous students while on clinical placement, with only four nursing or midwifery articles mentioning clinical placement support [34, 49, 53, 57].
While this accords with the findings of a previous review on Indigenous nurses [26], it is troubling because clinical placements are a core component of many health science degrees as well as preparing students for the workforce. As Milne et al. [26] states, "awareness of students' experience in this context is essential to their academic success" (p. 392).

Effective, long-term strategies to grow the Indigenous health workforce cannot start at university. Skills and knowledge learned at school are critical elements of the health workforce development pipeline (and therefore workforce development policies and university recruitment strategies) [72, 73]. Although out of scope of the current review, there needs to be a greater focus on increasing the number of Indigenous students completing high school, encouragement of Indigenous students to study science in high school, and support for students during their transition from high school to university $[64,72]$. In addition, there needs to be a focus on articulation and increasing the pathways and support available for students wishing to progress from VET health programs into graduate entry programs.

\section{Limitations}

Systematic reviews are inevitably limited by the quality and quantity of research available for inclusion. The literature was primarily descriptive in nature, with only 14 empirical studies identified, and while most studies made recommendations or described implemented strategies, none had tested an intervention aimed at improving retention. The lack of rigorous evaluations measuring the effectiveness of retention strategies for Indigenous health students has previously been identified [34, 72]. This study was also limited by the methodological quality of some articles. However, the limitations of included studies have been acknowledged and communicated through quality scores, allowing readers to take this into consideration. Furthermore, many of the included studies had small sample sizes (only one study had more than 33 participants) or gave limited data on the demographics of the population (8 studies only provided the students' field of study), which limits the generalizability of the findings. Over a third of articles (38\%) are more than a decade old, and pre-date the Australian Government Closing the Gap initiative to reduce inequalities in Indigenous life expectancy, mortality, education and employment [74]. Of greater concern is the observation that there has been no apparent increase in the rate of publication in this field (unlike the exponential increase observed within Indigenous health research [75]), suggesting that this is not a growing research priority. These limitations in the literature, with reports that are observational, descriptive and cross-sectional in nature, underscore the urgent need for robust evaluation and research in this area. 


\section{Implications}

Universities have an important role to play in addressing inequities in the Indigenous health workforce. It is hoped that findings from this review will be used by schools and faculties to inform the development of support strategies and programs that incorporate:

- The whole of student life; starting with recruitment and selection, continuing through pre-entry preparation and orientation, and including cultural, academic, social and economic support while at university, as well as considering point of departure.

- Opportunities for students to meet and connect with fellow Indigenous students during orientation and throughout their studies, whether through formal mentoring programs, student networks or informal social gatherings.

- Flexibility in delivery.

- Engagement with and input from local Indigenous communities and health services.

- Evaluation and assessment of efficacy, with the publication of results where possible, so that a body of 'best practice' evidence can be established.

In addition, schools and faculties need to adopt and communicate policies, guidelines and actions that address racism. The Universities Australia 'National best practice framework for Indigenous cultural competency in Australian universities' outlines guiding principles and specific recommendations with the aim of making Australian universities places where Indigenous students can "thrive and feel at home" ([71], p.7).

Government also has a role in delivering and supporting effective schemes that provides incentives and financial support for Indigenous students, and proactive policies that encourage universities to provide the additional supports needed by Indigenous students.

Clinical placements are a core component of many health science degrees. Despite this, we found no investigation of Indigenous students' experiences while on clinical placement and few reported strategies to support Indigenous students while on clinical placement. This highlights the need for further research in this area, with collaborations between academics and clinicians and between universities and health services, to establish the factors affecting success for Indigenous students while on placement and how best to support students, while at the same time preparing them for the workforce.

\section{Conclusions}

The enablers and barriers to Aboriginal and Torres Strait Islander student retention have been researched for 30 years. This systematic review, focussed on health science courses, reiterates the findings from a multitude of previous studies that the key factors affecting retention (as reported by students) are: family and peer support; competing obligations; academic preparation and prior educational experiences; access to the Indigenous Student Support Centre; financial hardship; and racism and discrimination. Historically, there has been little written about practical strategies to support Indigenous students. This review found that the most successful strategies implemented by nursing, health and medical science faculties to improve retention were multi-layered and started before the student commenced at university. Specific strategies included: culturally appropriate recruitment and selection processes; comprehensive orientation and pre-entry programs; building a supportive and enabling school culture; appointing Indigenous academics; developing mentoring and tutoring programs; flexible delivery of content; partnerships with the Indigenous Student Support Centre; providing social and financial support; and 'leaving the university door open' for students who leave before graduation to return.

The gap in the literature that became apparent is empirical research that measures the efficacy of strategies to improve retention. While commendable to see schools and faculties describing their many efforts, programs and strategies to improve retention, the evidence that supports the efficacy of these approaches is limited. Although trial designs are unrealistic, programs and strategies need to be evaluated with pre- and post-implementation measures, and assessed using both qualitative and quantitative data/ research. As stated by Best et al. [34] in 2014, "The underlying problem is not one of policy direction, but one of policy implementation. Little current literature provides discussion about best practice in achieving successful outcomes in graduating Indigenous nurses" (p. 61). And while it is tempting to look for a "magic bullet" in terms of implementing what seems most effective, it seems certain that a suite of measures implemented concurrently to provide support across multiple domains will most enable talented Indigenous people to overcome adversities and graduate as health professionals. The skills learnt while achieving this milestone will also be valuable as they enter the workforce, where retention of Indigenous health professionals remains an important concern [76].

\footnotetext{
Abbreviations

AIDA: Australian Indigenous Doctors' Association; CATSINaM: Congress of Aboriginal and Torres Strait Islander Nurses and Midwives; IALM: Indigenous Academic Liaison Midwife; INS: Indigenous Nursing Support; JBI T\&O: Joanna Briggs Institute Checklist for Text and Opinion; Medical Deans: Medical Deans Australia and New Zealand; MMAT: Mixed Methods Appraisal Tool;

PRISMA: Preferred Reporting Items for Systematic Review and Meta-Analysis; VET: Vocational education and training
}

\section{Acknowledgements}

The authors thank Genevieve Lai for her involvement in initial study discussions and preliminary literature searches and analysis. 


\section{Authors' contributions}

EVT contributed to conception and design, carried out acquisition and analysis of data, and drafted the manuscript. AL contributed to acquisition and analysis of data and manuscript revision. SCT contributed to study conception, design, and manuscript revision. All authors read and approved the manuscript.

\section{Funding}

The Western Australian Centre for Rural Health receives funding from a rural health workforce initiative of the Australian Government through the Commonwealth Department of Health. The views expressed in this publication are those of the authors and do not necessarily reflect the views of the funding agency.

\section{Availability of data and materials}

Not applicable.

Ethics approval and consent to participate

Not applicable.

\section{Consent for publication}

Not applicable.

\section{Competing interests}

The authors declare that they have no competing interests.

Received: 20 June 2019 Accepted: 19 August 2019

Published online: 02 September 2019

\section{References}

1. Department of the Prime Minister and Cabinet. Closing the Gap Prime Minister's report 2018. 2018. https://www.pmc.gov.au/sites/default/files/ publications/ctg-report-2018.pdf. Accessed 5 Mar 2019.

2. Australian Institute of Health and Welfare. The health and welfare of Australia's Aboriginal and Torres Strait Islander peoples: 2015. 2015. https://www.aihw. gov.au/reports/indigenous-health-welfare/indigenous-health-welfare-2015/ contents/indigenous-population-key-points Accessed 7 Mar 2019.

3. Matthews JD. Historical, social and biological understanding is needed to improve aboriginal health. Recent Adv Microbiol. 1997;5:257-334.

4. Vos T, Barker B, Begg S, Stanley L, Lopez AD. Burden of disease and injury in aboriginal and Torres Strait islander peoples: the indigenous health gap. Int J Epidemiol. 2009;38(2):470-7. https://doi.org/10.1093/ije/dyn240.

5. McLennan W, Madden R. The health and welfare of Australia's Aboriginal and Torres Strait Islander Peoples. Canberra; 1997. http://www.abs.gov.au/AUSSTATS/ abs@.nsf/DetailsPage/4704.01997?OpenDocument. Accessed 5 Mar 2019

6. Australian Department of Health and Ageing. National Aboriginal and Torres Strait Islander health plan 2013-2023. Canberra (AUST): Australian department of health and ageing; 2013. http://www.health.gov.au/internet/ main/publishing.nsf/content/B92E980680486C3BCA257BF0001BAF01/\$File/ health-plan.pdf. Accessed 5 Mar 2019

7. Wilkins R, Tjepkema M, Mustard C, Choinière R. The Canadian census mortality follow-up study, 1991 through 2001. Health Rep. 2008;19(3):25

8. Preston J. The urgency of postsecondary education for aboriginal peoples. Canadian J Educ Adm Policy. 2008;(86).

9. Boughton B. What is the connection between aboriginal education and aboriginal health? Casuarina: Cooperative Research Centre for Aboriginal and Tropical Health; 2000.

10. Review of higher education access and outcomes for Aboriginal and Torres Strait Islander people: final report. Department of Industry, Innovation, Science, Research and Tertiary Education (Australia). 2012. https://apo.org. au/node/31135. Accessed 14 Mar 2019.

11. Indigenous Nursing Education Working Group. Gettin em n keepin em : report of the Indigenous Nursing Education Working Group to the Commonwealth Department of Health and Ageing Office for Aboriginal and Torres Strait Islander Health. In: Report to the Commonwealth Department of Health and Ageing. Canberra: Canberra, ACT: Office for Aboriginal and Torres Strait Islander Health; 2002. https://www.catsinam.org. au/static/uploads/files/gettinem-wfiwjthfuvhk.pdf. Accessed 8 Nov 2018.

12. Stuart $L$, Nielsen A-M. Two aboriginal registered nurses show us why black nurses caring for black patients is good medicine. Contemp Nurse. 2011; 37(1):96-101. https://doi.org/10.5172/conu.2011.37.1.096.
13. Curtis E, Reid P. Indigenous health workforce development: challenges and successes of the vision 20:20 programme. ANZ J Surg. 2013;83(1-2):49-54. https://doi.org/10.1111/ans.12030.

14. Sullivan LW. Missing persons: minorities in the health professions, A Report of the Sullivan Commission on Diversity in the Healthcare Workforce: Sullivan Commission; 2004. http://health-equity.lib.umd.edu/40/1/Sullivan_ Final_Report_000.pdf. Accessed 14 Mar 2019

15. Anderson M, Lavallee B. The development of the first nations, Inuit and Métis medical workforce. Med J Aust. 2007;186(10):539-40. https://doi.org/1 0.5694/j.1326-5377.2007.tb01033.x.

16. DiGregorio KD, Farrington S, Page S. Listening to our students: understanding the factors that affect aboriginal and Torres Strait islander students' academic success. High Educ Res Dev. 2000;19(3):297-309. https:// doi.org/10.1080/758484344.

17. Australian Institute of Health and Welfare. Medical practitioners workforce 2015. 2016. https://www.aihw.gov.au/reports/workforce/medicalpractitioners-workforce-2015/contents/who-are-medical-practitioners. Accessed 14 Mar 2019

18. Australian Institute of Health and Welfare. Nursing and midwifery workforce 2015. 2016. https://www.aihw.gov.au/reports/workforce/nursing-andmidwifery-workforce-2015/contents/who-are-nurses-and-midwives. Accessed 14 Mar 2019

19. West R, Usher K, Foster K. Increased numbers of Australian indigenous nurses would make a significant contribution to 'closing the gap' in indigenous health: what is getting in the way? Contemp Nurse. 2010;36(12):121-30. https://doi.org/10.5172/conu.2010.36.1-2.121.

20. Kippen S, Ward B, Warren L. Enhancing indigenous participation in higher education health courses in rural Victoria. Australian J Indigenous Educ. 2006;35:1-10.

21. Minniecon D, Kong K. Healthy Futures: Defining best practice in the recruitment and retention of Indigenous medical students. Manuka: Australian Indigenous Doctors' Association; 2005. https://www.aida.org. au/wp-content/uploads/2017/08/AIDA-Healthy-Futures-Report.pdf. Accessed 13 Nov 2018

22. Gray J, Beresford Q. A 'formidable challenge': Australia's quest for equity in indigenous education. Aust J Educ. 2008;52(2):197-223. https://doi.org/10.11 77/000494410805200207

23. Bin-Sallik M. Aboriginal tertiary education in Australia: how well is it serving the needs of aborigines: Harvard University; 1989.

24. James $\mathrm{R}$, Devlin M. Improving indigenous outcomes and enhancing indigenous culture and knowledge in Australian higher education. Canberra: DEST; 2006. http://hdl.voced.edu.au/10707/56575. Accessed 14 Mar 2019

25. Bunda T, Zipin L, Brennan M. Negotiating university 'equity' from indigenous standpoints: a shaky bridge. Int J Incl Educ. 2012;16(9):941-57. https://doi.org/10.1080/13603116.2010.523907

26. Milne T, Creedy DK, West R. Integrated systematic review on educational strategies that promote academic success and resilience in undergraduate indigenous students. Nurse Educ Today. 2016;36:387-94. https://doi.org/10.1 016/j.nedt.2015.10.008.

27. Department of Education and Training. Selected Higher Education Statistics - Student Data. 2018. https://www.education.gov.au/studentdata. Accessed 8 Nov 2018

28. West R, Usher K, Buettner PG, Foster K, Stewart L. Indigenous Australians' participation in pre-registration tertiary nursing courses: a mixed methods study. Contemp Nurse. 2013;46(1):123-34. https://doi. org/10.5172/conu.2013.46.1.123.

29. Asmar C, Page S, Radloff A. Exploring anomalies in indigenous student engagement: findings from a National Australian Survey of undergraduates. High Educ Res Dev. 2015;34(1):15-29. https://doi.org/1 0.1080/07294360.2014.934334.

30. Gore J, Patfield S, Fray L, Holmes K, Gruppetta M, Lloyd A, et al. The participation of Australian indigenous students in higher education: a scoping review of empirical research, 2000-2016. Aust Educ Res. 2017:44(3): 323-55. https://doi.org/10.1007/s13384-017-0236-9.

31. Bourke C, Burden J, Moore S. Factors affecting performance of aboriginal and Torres Strait islander students at Australian universities: a case study. Canberra: Australian Government Publishing Service; 1996.

32. Nakata M, Nakata V, Chin M. Approaches to the Academic Preparation and Support of Australian Indigenous Students for Tertiary Studies. Australian J Indigenous Educ. 2008;37(Supplementary):137-45. 
33. Hearn S, Benton M, Funnell S, Marmolejo-Ramos F. Investigation of the factors contributing to indigenous students' retention and attrition rates at the University of Adelaide. Australian J Indigenous Educ. 2019:1-9. https:// doi.org/10.1017/jie.2019.5.

34. Best O, Stuart L. An aboriginal nurse-led working model for success in graduating indigenous Australian nurses. Contemp Nurse. 2014;48(1):59-66. https://doi.org/10.5172/conu.2014.48.1.59.

35. Cramer JH, Pugh JD, Slatyer S, Twigg DE, Robinson M. Issues impacting on enrolled nurse education for aboriginal and Torres Strait islander students: a discussion. Contemp Nurse. 2018:1-10. https://doi.org/10.1080/10376178.201 8.1493347.

36. Liberati A, Altman DG, Tetzlaff J, Mulrow C, Gøtzsche PC, loannidis JPA, et al. The PRISMA statement for reporting systematic reviews and meta-analyses of studies that evaluate healthcare interventions: explanation and elaboration. BMJ. 2009;339:b2700. https://doi.org/10.1136/bmj.b2700.

37. Hong QN, Pluye P, Fàbregues S, Bartlett G, Boardman F, Cargo M, et al. Mixed methods appraisal tool (MMAT), version 2018: Canadian Intellectual Property Office, Industry Canada; 2018. http:// mixedmethodsappraisaltoolpublic.pbworks.com/w/file/fetch/127916259/ MMAT_2018_criteria-manual_2018-08-01_ENG.pdf. Accessed 14 Mar 2019

38. Souto RQ, Khanassov V, Hong QN, Bush PL, Vedel I, Pluye P. Systematic mixed studies reviews: updating results on the reliability and efficiency of the mixed methods appraisal tool. Int J Nurs Stud. 2015;52(1):500-1. https:// doi.org/10.1016/j.jinurstu.2014.08.010.

39. Pluye P, Gagnon M-P, Griffiths F, Johnson-Lafleur J. A scoring system for appraising mixed methods research, and concomitantly appraising qualitative, quantitative and mixed methods primary studies in mixed studies reviews. Int J Nurs Stud. 2009;46(4):529-46.

40. Pace R, Pluye P, Bartlett G, Macaulay AC, Salsberg J, Jagosh J, et al. Testing the reliability and efficiency of the pilot mixed methods appraisal tool (MMAT) for systematic mixed studies review. Int J Nurs Stud. 2012:49(1):4753. https://doi.org/10.1016/j.jinurstu.2011.07.002.

41. McArthur A, Klugárová J, Yan H, Florescu S. Innovations in the systematic review of text and opinion. Int J Evidence-Based Healthcare. 2015;13(3):18895. https://doi.org/10.1097/xeb.0000000000000060.

42. Slatyer S, Cramer J, Pugh JD, Twigg DE. Barriers and enablers to retention of aboriginal diploma of nursing students in Western Australia: an exploratory descriptive study. Nurse Educ Today. 2016;42:17-22. https://doi.org/10.1016/ j.nedt.2016.03.026.

43. Cameron S, Robinson K. The experiences of Indigenous Australian psychologists at university. Australian Psychologist. 2014;49(1):54-62. https:// doi.org/10.1111/ap.12036.

44. Chur-Hansen A, Herbert P, Caruso J, Barrett R. Indigenous students entering a course in the health professions: a qualitative study of their aspirations and expectations. Aborig Is| Health Work J. 2008;32(5):19-24.

45. Ellender I, Drysdale M, Chesters J, Faulkner S, Kelly H, Turnbull L. When a dream becomes a nightmare: why do indigenous Australian medical students withdraw from their courses? Australian J Indigenous Educ. 2008;37:40-7.

46. Farrington S, Page S, DiGregorio KD. The things that matter: understanding the factors that affect the participation and retention of indigenous students in the Cadigal program at the Faculty of Health Sciences, University of Sydney. JANZSSA. 2001;18:40-55.

47. Garvey G, Rolfe IE, Pearson SA, Treloar C. Indigenous Australian medical students' perceptions of their medical school training. Med Educ. 2009; 43(11):1047-55. https://doi.org/10.1111/j.1365-2923.2009.03519.x.

48. Mills J, Felton-Busch C, Park T, Maza K, Mills F, Ghee M, et al. Supporting Australian Torres Strait Islander and Aboriginal nursing students using mentoring circles: An action research study. High Educ Res Dev. 2014;33(6): 1136-49. https://doi.org/10.1080/07294360.2014.911262.

49. Schulz PM, Dunne CL, Burdett-Jones D, Gamble NS, Kosiak MM, Neal $J M$, et al. Evaluation of strategies designed to enhance student engagement and success of indigenous midwifery students in an awayFrom-Base bachelor of midwifery program in Australia: a qualitative research study. Nurse Educ Today. 2018;63:59-63. https://doi.org/10.1 016/j.nedt.2018.01.026

50. Stuart L, Gorman D. The experiences of Indigenous health workers enrolled in a Bachelor of Nursing at a regional Australian university. AlterNative: An International Journal of Indigenous Peoples. 2015:11(1):29-44.

51. Usher K, Lindsay D, Miller M, Miller A. Challenges faced by indigenous nursing students and strategies that aided their progress in the course: a descriptive study. Contemp Nurse. 2005;19(1-2):17-31.
52. West R, Foster K, Stewart L, Usher K. Creating walking tracks to success: A narrative analysis of Australian Aboriginal and Torres Strait Islander nursing students' stories of success. Collegian. 2016;23(4):349-54. https://doi.org/10.1 016/j.colegn.2016.08.001

53. West R, Gamble J, Kelly J, Milne T, Duffy E, Sidebotham M. Culturally capable and culturally safe: caseload care for indigenous women by indigenous midwifery students. Women Birth. 2016;29(6):524-30. https://doi.org/10.1 016/j.wombi.2016.05.003.

54. Young J, Stupans I, Scutter S, Smith L. Retaining indigenous students within health sciences courses at the University of South Australia. Focus on Health Professional Education: A Multi-disciplinary Journal. 2007;9(1):33-43.

55. Fowler AC, Ewens B, Vafeas C, Delves L, Hayward C, Nannup N, et al. Closing the gap: a whole of school approach to aboriginal and Torres Strait islander inclusivity in higher education. Nurse Educ Pract. 2018;30:86-90. https://doi. org/10.1016/j.nepr.2018.04.001.

56. Harris JB, Hill B, Kiernan M. A model for increasing Indigenous participation in psychology degrees. Australian Psychologist. 2012;47(3):128-36. https:// doi.org/10.1111/j.1742-9544.2012.00066.x.

57. Hinton A, Chirgwin S. Nursing education: reducing reality shock for graduate indigenous nurses - It's all about time. Australian J Adv Nursing. 2010:28(1):60-6.

58. Holliday V, O'Mara P, Watts A. The Miroma Bunbilla Pre-entry to Medicine program for Aboriginal and Torres Strait Islander people. In: LIME Good Practice Case Studies Volume 3. LIME Good Practice Case Studies. Parkville: Onemda VicHealth Koori Health Unit, The University of Melbourne; 2015. p. 24-30.

59. Lawson KA, Armstrong RM. Weyden MBvd. Training indigenous doctors for Australia: shooting for goal. (special issue: indigenous health.). Med J Aust. 2007:186(10):547-50.

60. Meiklejohn B, Wollin JA, Cadet-James YL. Successful completion of the Bachelor of Nursing by Indigenous people. Australian Indigenous HealthBulletin. 2003;3(2).

61. Paul D. Creating change: building the capacity of the medical workforce in aboriginal health. ANZ J Surg. 2013;83(1-2):55-9. https://doi.org/10.1111/ans.12031.

62. Usher K, Lindsay D, Mackay W. An innovative nurse education program in the Torres Strait Islands. Nurse Educ Today. 2005;25(6):437-41. https://doi. org/10.1016/.inedt.2005.04.003.

63. Dudgeon P, Darlaston-Jones D, Phillips G, Newnham K, Brideson T, Cranney J, et al. Australian indigenous psychology education project : guidelines for increasing the recruitment, retention and graduation of aboriginal and Torres Strait islander psychology students. Canberra. 2016; Accessed 8 Nov 2018.

64. Medical Deans Australia and New Zealand, Australian Indigenous Doctors' Association. A Review of the Implementation of the Indigenous Health Curriculum Framework and the Healthy Futures Report within Australian Medical Schools. Sydney: Australian Indigenous Doctors' Association; 2012. https://medicaldeans.org.au/md/2018/07/Medical-Deans-AIDA-Review-FinalReport.pdf. Accessed 17 Jan 2019

65. Foxall D. Barriers in education of indigenous nursing students: a literature review. Nurs Prax N Z. 2013;29(3):31-7.

66. Gwynne K, Rojas J, Hines M, Bulkeley K, Irving M, McCowen D, et al. Customised approaches to vocational education can dramatically improve completion rates of Australian Aboriginal students. Australian Health Review. 2019. https://doi.org/10.1071/AH18051.

67. Guenther J, Bat M, Stephens A, Skewes J, Boughton B, Williamson F et al. Enhancing Training Advantage for Remote Aboriginal and Torres Strait Islander Learners. Research Report. National Centre for Vocational Education Research Ltd, P.O. Box 8288, Stational Arcade, Adelaide, SA 5000, Australia. 2017. https:// www.ncver.edu.au/_data/assets/pdf_file/0037/497368/Enhancing-trainingadvantage-for-remote-ATSI-learners.pdf. Accessed 9 May 2019.

68. Godfrey E, King R. Scoping the Opportunities to Aid Recruitment and Retention of Indigenous Students in Engineering. Sydney: Proceedings of the 21st Annual Conference for the Australasian Association for Engineering Education: University of Technology; 2010. p. 8-15.

69. Howlett C, Seini M, Matthews C, Dillon B, Hauser V. Retaining indigenous students in tertiary education: lessons from the Griffith School of Environment. Australian J Indigenous Educ. 2008;37(1):18-27. https://doi. org/10.1017/S1326011100016057.

70. Rodgers-Falk P, Vidler R. Growing the number of aboriginal and Torres Strait islander law graduates: barriers to the profession. Canberra: Department of Education, Employment and Workplace Relations; 2012. https://docs. education.gov.au/documents/growing-number-aboriginal-and-torres-straitislander-law-graduates-barriers-profession. Accessed 9 May 2019 
71. Universities Australia. National best practice framework for indigenous cultural competency in Australian universities. Universities Australia Canberra 2011. https://www.universitiesaustralia.edu.au/uni-participation-quality/ Indigenous-Higher-Education/Indigenous-Cultural-Compet\#.XNE8bzAzZhE. Accessed 7 May 2019.

72. Curtis E, Wikaire E, Stokes K, Reid P. Addressing indigenous health workforce inequities: a literature review exploring 'best' practice for recruitment into tertiary health programmes. Int J Equity Health. 2012;11(13).

73. Ratima M, Brown R, Garrett N, Wikaire E, Ngawati R, Aspin C et al. Rauringa raupa: recruitment and retention of Maori in the health and disability workforce. 2008. https://www.health.govt.nz/system/files/documents/ publications/maori_health_workforce_110708low_with_cover.pdf. Accessed 9 May 2019.

74. Australian Indigenous HealthInfoNet. History of Closing the Gap. 2018. https://healthinfonet.ecu.edu.au/learn/health-system/closing-the-gap/ history-of-closing-the-gap/. Accessed 18 June 2019.

75. Kinchin I, Mccalman J, Bainbridge R, Tsey K, Lui FW. Does indigenous health research have impact? A systematic review of reviews. Int J Equity Health. 2017;16(1):52. https://doi.org/10.1186/s12939-017-0548-4.

76. Lai GC, Taylor EV, Haigh MM, Thompson SC. Factors affecting the retention of indigenous Australians in the health workforce: a systematic review. Int J Environ Res Public Health. 2018:15(5):914.

\section{Publisher's Note}

Springer Nature remains neutral with regard to jurisdictional claims in published maps and institutional affiliations.

Ready to submit your research? Choose BMC and benefit from:

- fast, convenient online submission

- thorough peer review by experienced researchers in your field

- rapid publication on acceptance

- support for research data, including large and complex data types

- gold Open Access which fosters wider collaboration and increased citations

- maximum visibility for your research: over $100 \mathrm{M}$ website views per year

At $\mathrm{BMC}$, research is always in progress.

Learn more biomedcentral.com/submissions 